\title{
Quasi-decadal spectral peaks of tropical western Pacific SSTs as a precursor for tropical cyclone threat
}

\author{
Shih-Yu Wang ${ }^{1}$ and Adam J. Clark ${ }^{2}$ \\ Received 16 July 2010; revised 8 September 2010; accepted 21 September 2010; published 9 November 2010.
}

[1] A recent study identified significant spectral peaks in sea surface temperatures (SSTs) at quasi-decadal frequency bands, which were unique to the tropical western Pacific (TWP). Using the multitaper method for spectral and coherence analysis, this study finds that the TWP SSTs at these quasi-decadal time scales are coherent with western Pacific tropical cyclone threat [as measured by the power dissipation index (PDI)], but that the PDI lags TWP SSTs by about two years. Thus, the quasi-decadal peaks in TWP SSTs may be a precursor for enhanced tropical cyclone threat two years later. Composite analyses are shown to illustrate how areal tropical cyclone frequencies and relevant atmospheric fields evolve following the quasidecadal peaks in TWP SSTs. The fields during peak PDI years strongly resemble those observed during El Niño events. Citation: Wang, S.-Y., and A. J. Clark (2010), Quasidecadal spectral peaks of tropical western Pacific SSTs as a precursor for tropical cyclone threat, Geophys. Res. Lett., 37, L21810, doi:10.1029/2010GL044709.

\section{Introduction}

[2] To determine changes in the potential destructiveness of tropical cyclones over time, Emanuel [2005] introduced the power dissipation index (PDI), defined as

$$
\mathrm{PDI} \equiv \int_{0}^{\tau} \mathrm{V}_{\max }^{3} \mathrm{dt}
$$

where $\mathrm{V}_{\max }$ is the maximum sustained wind speed and $\tau$ is the lifetime of a tropical cyclone. The PDI provides a preferable measure of tropical cyclone threat over the use of storm frequency or intensity alone. Later studies [Klotzbach, 2006; Sriver and Huber, 2006; Emanuel, 2007; Wu et al., 2008] further evaluated the PDI and found general agreements with Emanuel [2005] that tropical cyclone threat has indeed increased globally associated with the increasing sea surface temperature (SST). Emanuel [2005] noted that the increase in PDI is not fully explained by increasing SSTs and explain that other factors (e.g., vertical wind shear, moist static energy, and sub-surface ocean temperatures) are also important. Furthermore, a number of studies argue that recent increases in PDI are a part of large decadal variability [e.g., Chan, 2006] and/or an artifact of systematic under-estimates of tropical cyclone intensities during the earlier portion of tropical cyclone records [Landsea et al., 2006; Kossin et al.,

\footnotetext{
${ }^{1}$ Utah Climate Center, Utah State University, Logan, Utah, USA. USA.

${ }^{2}$ National Severe Storms Laboratory, NOAA, Norman, Oklahoma,
}

Copyright 2010 by the American Geophysical Union. 0094-8276/10/2010GL044709
2007]. Nevertheless, as illustrated in Figure 1a, since the 1970 s the PDI has increased coherently with the typhoonseason SST within the area $130^{\circ} \mathrm{E}-180^{\circ}$ and $5^{\circ} \mathrm{N}-15^{\circ} \mathrm{N}$, denoted hereafter as the tropical western Pacific (TWP). In addition, as indicated by pairs of blue and red arrows in Figure 1a, periodic features emerge from the smoothed PDI and TWP SST time series, with the peaks of the PDI consistently lagging the peaks of SST by about two years.

[3] Such periodic features echo the characteristic quasidecadal signals observed in the tropical Pacific [e.g., Tourre et al., 2001; White and Liu, 2008; Meehl et al., 2009; Wang et al., 2010] which likely affect the tropical cyclone frequency and intensity. The noted lagged relationship in Figure la therefore opens up a possibility that increases in the TWP SST may be a precursor to increases in tropical cyclone power a couple of years later, a previously undocumented feature that is examined herein. In the North Atlantic, similar quasi-decadal variability is also apparent, but the PDI and SST variations there appear coherent without discernable time lags [Emanuel, 2005, Figure 1]. Thus, we will focus on the western Pacific to investigate this quasi-decadal variability and the unique phase shifts between the PDI and the TWP SST. Implications from the analysis will be discussed.

\section{Data}

[4] This study uses the six-hour "best track" data compiled by the US Navy's Joint Typhoon Warning Center (JTWC) for tropical cyclone wind speeds. To cope with the changes in the measurement of minimum surface pressure and maximum sustained surface wind during 1973 [e.g., Landsea, 1993], we correct the pre-1973 JTWC wind speeds using

$$
V_{\max }^{\prime}=0.228 V_{\max }^{1.288}
$$

(unit in meters per second) and apply a smoothing for the transition between 1959 and 1972 as described by Emanuel [2005, online supplement]. Based on equation (1), the corrected wind speed of all tropical cyclones is then accumulated over a year to obtain the PDI. Other data sets include the Met Office Hadley Centre's sea surface temperature (HadSST2) [Rayner et al., 2006], the NCEP/NCAR Global Reanalysis [Kalnay et al., 1996], and the gauge and satellite-based Precipitation REConstruction over Ocean (PREC/O) [Xie et al., 2002]. The analysis period spans 1960-2009.

\section{Results}

[5] To examine the dominant mode of the PDI and the TWP SST and their phase shifts observed in Figure 1a, the multitaper method (MTM) of spectral/coherence analysis is applied. Introduced by Mann and Park [1996], the MTM spectral/coherence analysis provides an optimally low-variance, 

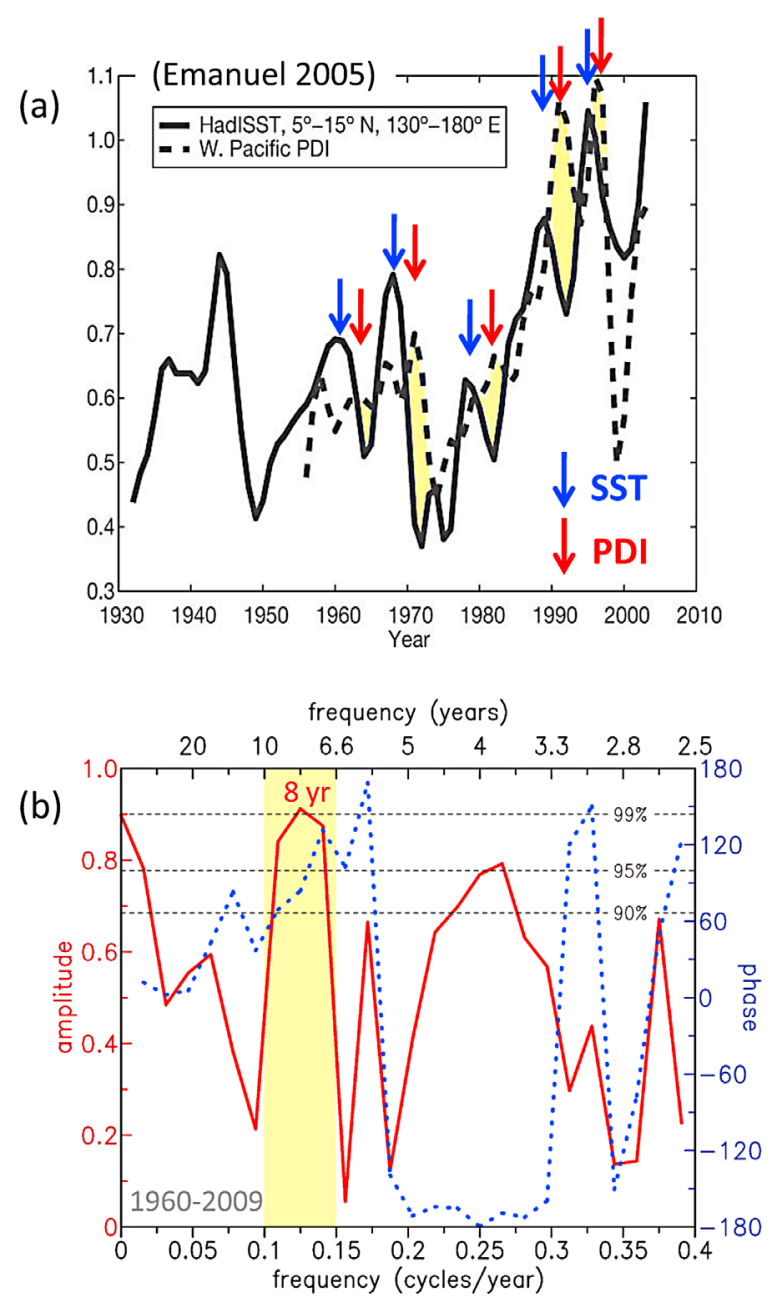

Figure 1. (a) The western Pacific PDI (solid curve) and July-November SST (dashed curve) averaged over a domain bounded in $130^{\circ} \mathrm{E}-180^{\circ}$ and $5^{\circ} \mathrm{N}-15^{\circ} \mathrm{N}$ (i.e. the TWP region). The PDI is multiplied by a factor of $8.3 \times 10^{-13}$ and the SST is offset by a constant. The peaks of quasidecadal variability in the PDI and SST are indicated respectively by blue and red arrows. Adopted from Emanuel [2005] with permission. (b) The MTM spectral/coherence amplitude (red solid curve) and phase (blue dotted curve) between the annual PDI and the July-November SST time series for the period of 1960-2009. Horizontal dashed lines denote $90 \%, 95 \%$, and $99 \%$ confidence limits from bootstrap resampling. Note that the phase lags of $180^{\circ}$ and $-180^{\circ}$ are the same. The phase difference at $0.1<f<0.15$ has the TWP SST leading the PDI.

high-resolution spectral estimate for two time series. As shown in Figure 1b, a high degree of coherence between the PDI and the TWP SST appears in three frequency bands: the multidecadal band reflecting the concurrent long term trends as argued by Emanuel [2005] and subsequent studies, the quasidecadal (7-10 year) band depicting the "pairs of peaks" as illustrated in Figure 1a, and the interannual (3-5 year) band corresponding to the El Niño-Southern Oscillation (ENSO) signals [e.g., Chan, 2000]. In particular, the coherence amplitude at 8 years is significant at the $99 \%$ confidence level with a $90^{\circ}$ (or quadrature) phase difference, supporting the afore- mentioned time lag between the PDI and the TWP SST of 2 years (i.e. a quarter-phase of an 8 year cycle). Meanwhile, the interannual mode reveals a steady phase difference of $-180^{\circ}$, signaling an out-of-phase relationship. This feature is consistent with the fact that intense tropical cyclones tend to be more active during El Niño years [e.g., Camargo and Sobel, 2005] when the TWP SST anomalies appear negative [cf. Chen et al., 2006, Figure 6].

[6] A recent study by Wang et al. [2010] noted that, specifically in the TWP and NINO4 regions $\left(160^{\circ} \mathrm{E}-150^{\circ} \mathrm{W}\right.$, $\left.5^{\circ} \mathrm{S}-5^{\circ} \mathrm{N}\right)$, the SST variations exhibit significant spectral peaks at 8 and 12 years; these low frequency signals are not as strong in the eastern tropical Pacific where ENSO is defined. Focusing on the quasi-decadal oscillation, Wang et al. [2010] found that the atmospheric circulation responses are not confined to just the warm/cold phases of the oscillation (which is determined by SST anomalies in the NINO4 region), but are also induced during the transition periods between the warm and cold phases. To examine the circulation anomalies responding to the 8 year "oscillations" in the PDI and SST, we perform a composite analysis on fields of SST, wind, moisture, and precipitation. A 1-2-1 smoother is applied on all variables twice in succession, following Emanuel [2005], in order to minimize the interannual variability. After the smoothing, the peak PDI years during the analysis period are 1964, 1971, 1982, 1987, 1991, 1996, and 2004; four out of these seven years are El Niño events. This agrees with the observation by Camargo and Sobel [2005] that the Accumulated Cyclone Energy, defined as the sum of $V_{\text {max }}^{2}$, is greatly affected by ENSO. Finally, multi-decadal signals are eliminated by applying the 25 year lowpass filter [Mann, 2004] on all variables and then using the residuals for the composite analysis; this minimizes the interdecadal variability in the PDI as argued by Chan [2006]. Except for the PDI which is accumulated annually, all variables are July-November averages corresponding to the typhoon season.

[7] The composite anomalies of SST and surface velocity potential (Figure 2a) show that, during the peak PDI years (Yr-0), the SST pattern resembles the warm-phase ENSO with significant warming over the NINO3.4 region $\left(170^{\circ} \mathrm{W}-\right.$ $\left.120^{\circ} \mathrm{W}, 5^{\circ} \mathrm{S}-5^{\circ} \mathrm{N}\right)$ associated with robust surface convergence. This surface convergence zone extends westward covering the TWP region where intense tropical cyclones tend to develop. One year prior to the peak PDI years (Yr-1), both the SST warming and surface convergence patterns are displaced slightly westward relative to $\mathrm{Yr}-0$, covering the NINO4 region and part of the TWP. Finally, two years before the peak PDI years (Yr-2), the equatorial SST anomalies are weak while well-organized warming occurs in and around the TWP region, corresponding to the quasi-decadal peaks in the TWP SST (cf. Figure 1a). This warming pattern is accompanied by organized surface convergence which is arguably a response of surface winds to the warm SST-induced upward heat flux, as was proposed by Lindzen and Nigam [1987].

[8] Wang et al. [2010] noted that the phase difference between decadal-scale SST variations in the TWP and the NINO4 region is also $90^{\circ}$, suggesting that the evolution of the SST anomalies occurs in the sequence that takes place over the TWP before moving to the NINO4 region 2-3 years later. These features are in good agreement with the eastward 

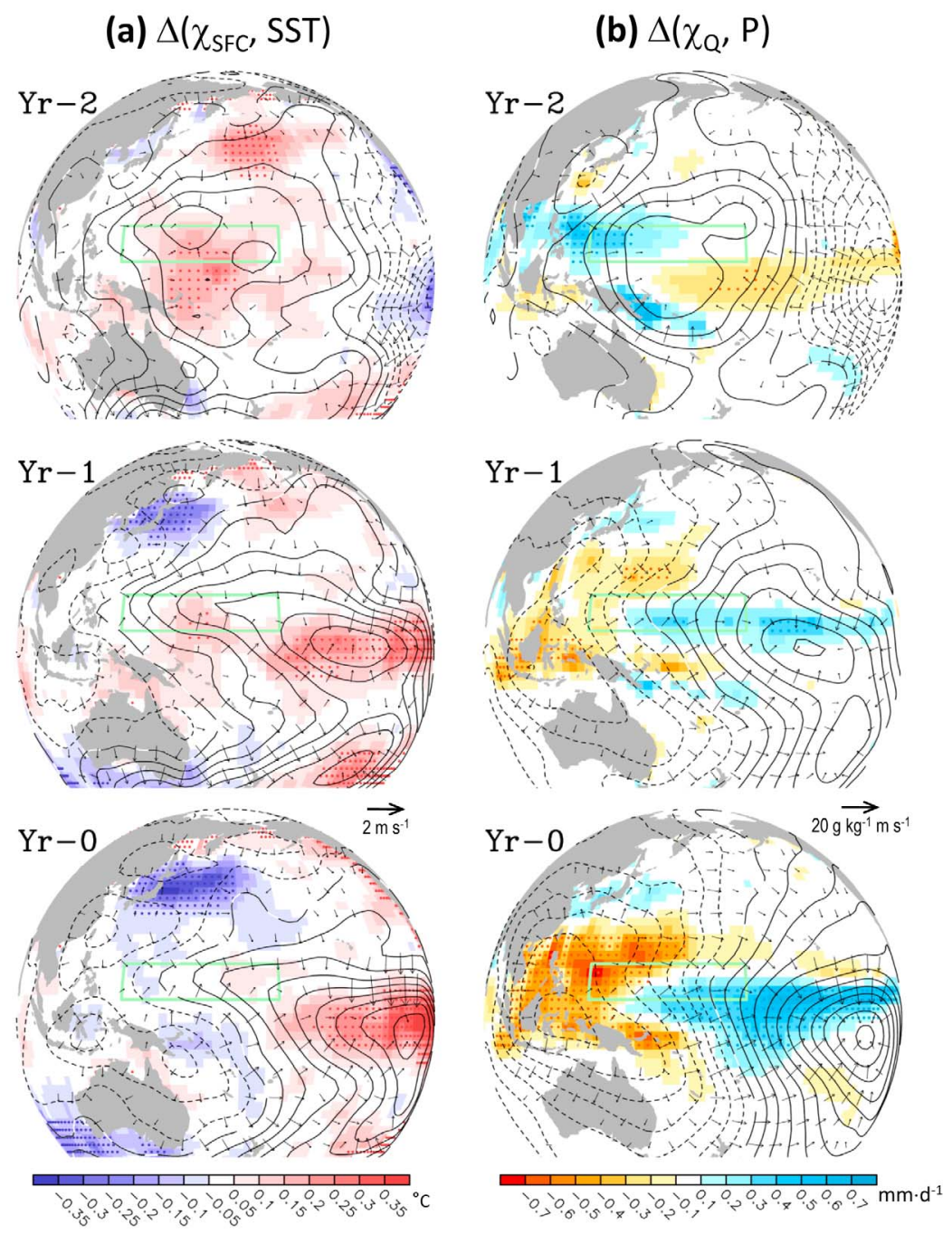

Figure 2. Composite anomalies of (a) surface velocity potential ( $\chi_{\mathrm{SFC}}$; contours) superimposed with divergent winds (vectors) and sea surface temperature (shadings), and (b) moisture flux velocity potential ( $\chi_{\mathrm{Q}}$; contours) superimposed with divergent water vapor flux (vectors) and precipitation (shadings) during the PDI peak years (Yr-0) and the preceding two years (Yr-1 and Yr-2). Dotted areas represent the SST and precipitation values at the 95\% confidence level based on t-test. Only vectors at the $90 \%$ confidence level are plotted. Contour intervals are $10^{7} \mathrm{~m}^{2} \mathrm{~s}^{-1}$ in Figure $2 \mathrm{a}$ and $10^{9} \mathrm{~g} \mathrm{~kg}^{-1} \mathrm{~m}^{2} \mathrm{~s}^{-1}$ in Figure $2 \mathrm{~b}$. The zero contours are shown as broken lines. The TWP region is outlined by the light green box.

migrations of SST anomalies and surface convergence as revealed in Figure 2a. The propagation of SST anomalies is also consistent with Zhang and Levitus [1997], who noted a decadal-scale eastward propagation of the SST anomalies across the tropical Pacific in response to the anomaly decadalscale cycle circulating around the subtropical gyre. To verify the composite results, we also perform a lagged regression analysis using the 6-11 year bandpass filtered SST and surface velocity potential regressing upon the filtered PDI. The results (not shown) depict consistent spatial distributions and eastward migrations as those in Figure 2a, including the El Niño-like pattern in $\mathrm{Yr}-0$ and the organized TWP warming in $\mathrm{Yr}-2$.

[9] Such evolutions and the atmospheric responses are investigated further by a similar composite analysis on precipitation and the water vapor flux $\left[\vec{Q} \equiv \int_{p_{S}} 300 \mathrm{mb}(\vec{V} \cdot q) d p\right.$ where $q$ is specific humidity, $\vec{V}$ is tropospheric winds, and $p$ is pressure level]. Following the derivation of Chen [1985], the water vapor flux is converted into potential function,

$$
\chi_{Q}=\nabla^{-2}(\nabla \cdot \vec{Q})
$$

and streamfunction,

$$
\psi_{Q}=\nabla^{-2}(\vec{k} \cdot \nabla \times \vec{Q}) .
$$

Based on the water vapor budget equation, the variable $\chi_{Q}$ provides a good approximation for the precipitation maintenance in the large-scale perspective [Chen, 1985]. The purpose of adopting the water vapor flux is to examine to what extent the presumably SST-induced surface convergence contributes to the precipitation anomalies and, in turn, verify the SST analysis. 
(a) $\psi_{Q}, \mathrm{TC}($ Cat 3-5)
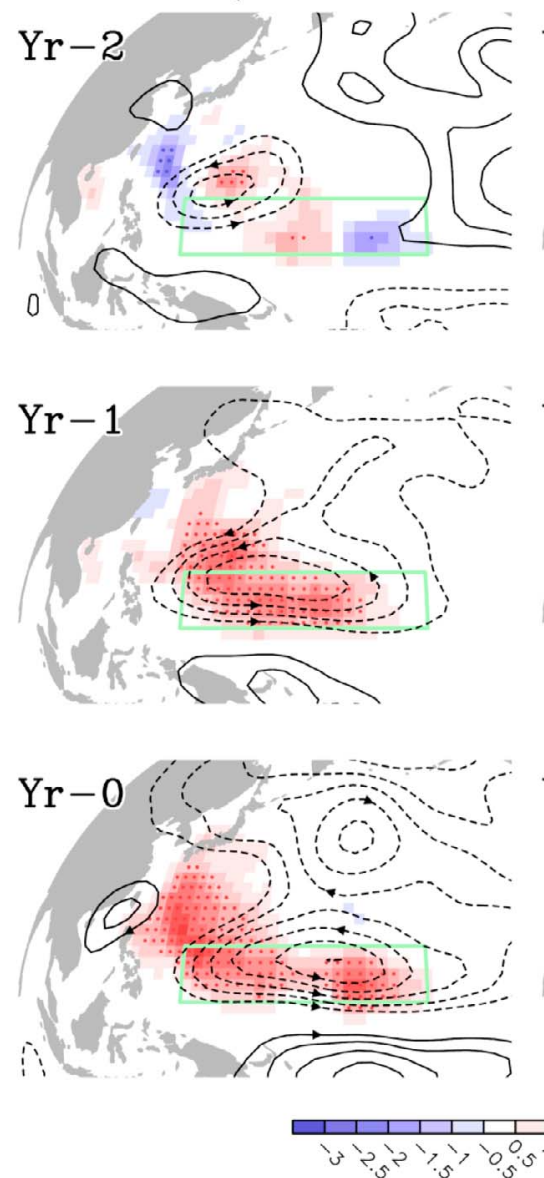

(b) $\psi_{\mathrm{Q}}, \mathrm{TC}($ Cat 0-2)
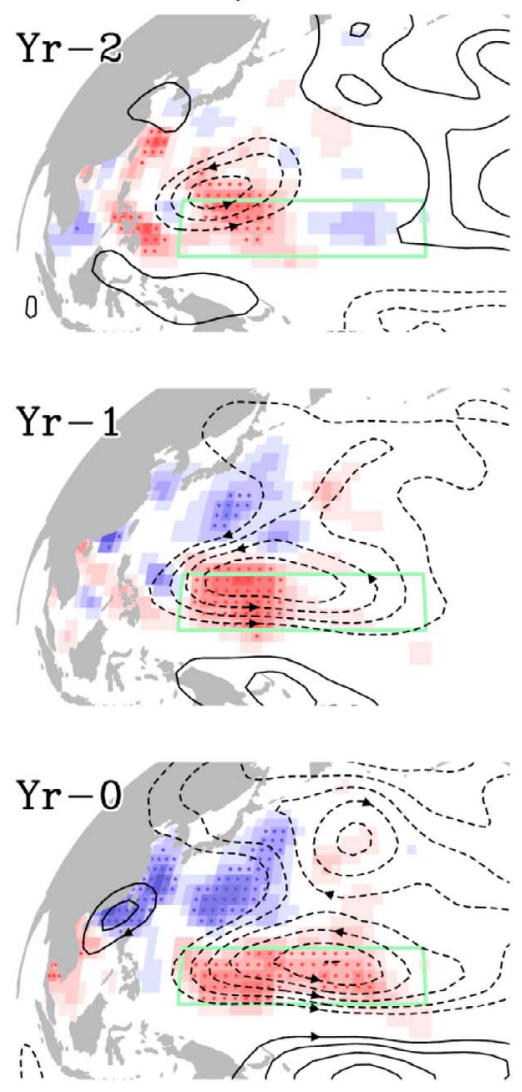

Figure 3. Composite anomalies of moisture flux streamfunction ( $\psi_{\mathrm{Q}}$; contours) superimposed with (a) Category (Cat) 3-5 and (b) Category 0-2 tropical cyclone frequency (shadings) during the PDI peak years (Yr-0) and the preceding two years (Yr-1 and Yr-2). Dotted areas represent tropical cyclone frequency anomalies at the $90 \%$ confidence level based on t-test. Contour intervals are $2.5 \times 10^{9} \mathrm{~g} \mathrm{~kg}^{-1} \mathrm{~m}^{2} \mathrm{~s}^{-1}$. The zero contours and the next positive and negative contours are omitted. The TWP region is outlined by the light green box.

[10] During Yr-0 (Figure 2b), an El Niño-like pattern emerges with significantly increased precipitation to the west of the NINO3.4 warming and decreased precipitation over much of the western Pacific and Southeast Asia. The increased precipitation is distributed over the maximum gradients of the SST anomalies while the decreased precipitation corresponds to the warm pool, which are features characteristic of ENSO [Clarke, 2008]. Moreover, positive (negative) precipitation anomalies are phase coincident with the converging (diverging) zones of $\chi_{Q}$ which, in general, satisfies the precipitation maintenance (i.e. $-\nabla \cdot \vec{Q} \approx P$ ). Noteworthy is the consistent spatial distribution between surface velocity potential and $\chi_{Q}$ in all three phases, as well as the convergence center north of the equator in $\mathrm{Yr}-2$. These features verify that changes in the SST anomalies form corresponding changes in the atmospheric circulations which, subsequently, would affect tropical cyclone power.

[11] To illustrate how the behavior of tropical cyclones reflects the evolution of fields shown in Figure 2, the composite circulation pattern of $\psi_{Q}$ from equation (4) and the areal frequencies of tropical cyclones are shown in Figure 3. Here, the tropical cyclone frequency is constructed on a $2^{\circ} \times 2^{\circ}$ grid mesh for each category from 0 (tropical depression) to 5, accumulated annually from the 6-hour track data. In Yr-0 (Figure 3a), a robust cyclonic circulation forms over the TWP region, accompanied by significant increases in the Category 3-5 (i.e. intense) tropical cyclone frequency throughout the western North Pacific. This cyclonic circulation delineates the deepened monsoon trough in the TWP region providing greater horizontal shear and higher moisture content in the monsoon westerlies, which are both favorable to tropical cyclone formation [Lander, 1994; Holland, 1995]. This result also supports the argument of Chan [2006] that the PDI variations are more likely a response to the atmospheric environment over the WTP (i.e. vorticity, shear, moist static energy) rather than being driven by the local SST anomalies. In the meantime, the frequency of weak (Category 0-2) tropical cyclones exhibits an anomalous dipole (Figure 3b), with increased activity within the TWP (due to the deepened monsoon trough) and decreased activity over the ocean between Japan and the Philippines (due to the anticyclonic circulation anomaly). These $\mathrm{Yr}-0$ features are consistent with those observed during ENSO years [Chen et al., 2006]. Two years earlier (Yr-2), a weaker yet discernable cyclonic circulation forms near the Philippine Sea with increased tropical cyclone frequency to 
the southeast and decreased frequency to the northwest. The increased tropical cyclone frequency coincides with the SST warming and surface convergence (Figure 2). In Yr-1, the composite patterns basically depict the transition between Yr-2 and Yr-0.

\section{Discussion}

[12] The above analysis on independent data sources provides substantial evidence for the lagged relationship between the quasi-decadal PDI and TWP SST variations. An intuitive question is how the quasi-decadal variation is formed. It has been noted that the Pacific SST variability consists of four major spectrums in the multi-decadal (25+ year), quasi-decadal (8-15 year), interannual and biannual frequency bands [e.g., Allan, 2000]. The 8 year spectrum identified in this study is only significant in the western Pacific [Wang et al., 2010]. The causes of the Pacific (inter)decadal variability are the subject of much debate, having developed into three competing theories of stochastic atmospheric forcing, the tropical delayed oscillator (oceanic forcing), and tropical-midlatitude decadal interaction (atmosphere-ocean feedback) [e.g., Miller and Schneider, 2000; Latif, 2006]. The quasi-decadal variability is rather intricate, because external forcing such as the solar irradiance cycle also plays a role [White and Liu, 2008; Meehl et al., 2009]. These subjects are beyond the scope of this study. Nevertheless, the delayed coupling between the PDI and the TWP SST in the quasi-decadal timescale, along with the corresponding circulation and precipitation anomalies, has an optimistic implication on the predictability of tropical cyclone threat out to two years. Further work is advised to improve understanding of Pacific decadal variability, which could possibly lead to further gains in seasonal tropical cyclone predictability.

[13] Acknowledgments. Valuable comments offered by Kerry Emanue are appreciated. S.Y.W. is supported by the Utah Climate Center, Utah State University, while A.J.C. is supported through a National Research Council Post-doctoral Award.

\section{References}

Allan, R. (2000), ENSO and climatic variability in the last 150 years, in El Niño and the Southern Oscillation: Multiscale Variability, Global and Regional Impacts, edited by H. F. Diaz and V. Markgrav, pp. 3-56, Cambridge Univ. Press, New York, doi:10.1017/CBO9780511573125.002.

Camargo, S. J., and A. H. Sobel (2005), Western North Pacific tropical cyclone intensity and ENSO, J. Clim., 18, 2996-3006, doi:10.1175/ JCLI3457.1.

Chan, J. C. L. (2000), Tropical cyclone activity over the western North Pacific associated with El Niño and La Niña events, J. Clim., 13, 2960-2972, doi:10.1175/1520-0442(2000)013<2960:TCAOTW >2.0. $\mathrm{CO} ; 2$.

Chan, J. C. L. (2006), Comment on "Changes in tropical cyclone number, duration, and intensity in a warming environment", Science, 311, 1713, doi:10.1126/science.1121522.

Chen, T.-C. (1985), Global water vapor flux and maintenance during FGGE, Mon. Weather Rev., 113, 1801-1819, doi:10.1175/1520-0493 (1985) $113<1801:$ GWVFAM>2.0.CO;2.

Chen, T.-C., S.-Y. Wang, and M.-C. Yen (2006), Interannual variation of the tropical cyclone activity over the western North Pacific, J. Clim., 19, 5709-5720, doi:10.1175/JCLI3934.1.

Clarke, A. J. (2008), An Introduction to the Dynamics of El Nino and the Southern Oscillation, 308 pp., Elsevier, New York.

Emanuel, K. (2005), Increasing destructiveness of tropical cyclones over the past 30 years, Nature, 436, 686-688, doi:10.1038/nature03906.
Emanuel, K. (2007), Environmental factors affecting tropical cyclone power dissipation, J. Clim., 20, 5497-5509, doi:10.1175/2007JCLI1571.1.

Holland, G. J. (1995), Scale interaction in the western Pacific monsoon, Meteorol. Atmos. Phys., 56, 57-79, doi:10.1007/BF01022521.

Kalnay, E., et al. (1996), The NCEP/NCAR 40-year reanalysis project, Bull. Am. Meteorol. Soc., 77, 437-471, doi:10.1175/1520-0477(1996) 077<0437:TNYRP $>2.0$.CO;2.

Klotzbach, P. J. (2006), Trends in global tropical cyclone activity over the past twenty years (1986-2005), Geophys. Res. Lett., 33, L10805, doi:10.1029/2006GL025881.

Kossin, J. P., K. R. Knapp, D. J. Vimont, R. J. Murnane, and B. A. Harper (2007), A globally consistent reanalysis of hurricane variability and trends, Geophys. Res. Lett., 34, L04815, doi:10.1029/2006GL028836.

Lander, M. A. (1994), Description of a monsoon gyre and its effects on the tropical cyclones in the western North Pacific during August 1991, Weather Forecast., 9, 640-654, doi:10.1175/1520-0434(1994) $009<0640$ :DOAMGA $>2.0 . \mathrm{CO} ; 2$.

Landsea, C. W. (1993), A climatology of intense (or major) Atlantic hurricanes, Mon. Weather Rev., 121, 1703-1713, doi:10.1175/1520-0493 (1993) $121<1703$ :ACOIMA>2.0.CO;2.

Landsea, C. W., B. A. Harper, K. Hoarau, and J. A. Knaff (2006), Can we detect trends in extreme tropical cyclones?, Science, 313, 452-454, doi: $10.1126 /$ science. 1128448 .

Latif, M. (2006), On North Pacific multidecadal climate variability, $J$. Clim., 19, 2906-2915, doi:10.1175/JCLI3719.1.

Lindzen, R. S., and S. Nigam (1987), On the role of sea surface temperature gradients in forcing low-level winds and convergence in the tropics, $J$. Atmos. Sci., 44, 2418-2436, doi:10.1175/1520-0469(1987)044<2418: OTROSS $>2.0 . \mathrm{CO} ; 2$.

Mann, M. E. (2004), On smoothing potentially non-stationary climate time series, Geophys. Res. Lett., 31, L07214, doi:10.1029/2004GL019569.

Mann, M., and J. Park (1996), Greenhouse warming and changes in the seasonal cycle of temperature: Model versus observations, Geophys. Res. Lett., 23, 1111-1114, doi:10.1029/96GL01066.

Meehl, G. A., J. M. Arblaster, K. Matthes, F. Sassi, and H. van Loon (2009), Amplifying the Pacific climate system response to a small 11-year solar cycle forcing, Science, 325, 1114-1118, doi:10.1126/science. 1172872.

Miller, J. A., and N. Schneider (2000), Interdecadal climate regime dynamics in the North Pacific Ocean: Theories, observations and ecosystem impacts, Prog. Oceanogr., 47, 355-379, doi:10.1016/S0079-6611(00) 00044-6.

Rayner, N. A., et al. (2006), Improved analyses of changes and uncertainties in sea surface temperature measured in situ since the mid-nineteenth century: The HadSST2 dataset, J. Clim., 19, 446-469, doi:10.1175/ JCLI3637.1.

Sriver, R., and M. Huber (2006), Low frequency variability in globally integrated tropical cyclone power dissipation, Geophys. Res. Lett., 33, L11705, doi:10.1029/2006GL026167.

Tourre, Y., B. Rajagopalan, Y. Kushnir, M. Barlow, and W. White (2001), Patterns of coherent decadal and interdecadal climate signals in the Pacific Basin during the 20th century, Geophys. Res. Lett., 28, 2069 2072, doi:10.1029/2000GL012780.

Wang, S.-Y., R. R. Gillies, L. E. Hipps, and J. Jin (2010), A transitionphase teleconnection of the Pacific quasi-decadal oscillation, Clim. Dyn., doi:10.1007/s00382-009-0722-5, in press.

White, W. B., and Z. Liu (2008), Resonant excitation of the quasi-decadal oscillation by the 11-year signal in the Sun's irradiance, J. Geophys. Res., 113, C01002, doi:10.1029/2006JC004057.

Wu, L., B. Wang, and S. A. Braun (2008), Implications of tropical cyclone power dissipation index, Int. J. Climatol., 28, 727-731, doi:10.1002/ joc. 1573 .

Xie, P., M. Chen, J. E. Janowiak, P. A. Arkin, and T. M. Smith (2002), Global oceanic precipitation from 1948 to the present: A reconstruction of historical gauge observations, paper presented at 13th Symposium on Global Changes and Climate Variations, Am. Meteorol. Soc., Orlando, Fla.

Zhang, R.-H., and S. Levitus (1997), Structure and cycle of decadal variability of upper-ocean temperature in the North Pacific, J. Clim., 10, 710-727, doi:10.1175/1520-0442(1997)010<0710:SACODV>2.0.CO;2.

S.-Y. Wang, Utah Climate Center, Utah State University, Logan, UT 84322, USA. (simon.wang@usu.edu)

A. J. Clark, National Severe Storms Laboratory, NOAA, 120 David L Boren Blvd., Norman, OK 73072, USA. 